\title{
A Unique Case of Primary Extranodal Non-Hodgkin's Lymphoma of the Lacrimal Sac with Extension to Ipsilateral Nasal Cavity
}

Himanshu Kumar Mittal

\begin{abstract}
The primary lacrimal sac involvement by malignant tumors is uncommon. The most commonly seen malignant tumors of the lacrimal sac are those of epithelial origin. Primary extranodal non-Hodgkin's lymphoma (PE-NHL) of the lacrimal sac is rare. We hereby present a rare case of primary non-Hodgkin's lymphoma (NHL) of the lacrimal sac with extension to the ipsilateral nasal cavity through the nasolacrimal duct.
\end{abstract}

Keywords: Extranodal, Lacrimal sac, Non-Hodgkin's lymphoma.

How to cite this article: Mittal HK. A Unique Case of Primary Extranodal Non-Hodgkin's Lymphoma of the Lacrimal Sac with Extension to Ipsilateral Nasal Cavity. Int J Otorhinolaryngol Clin 2014;6(3):103-105.

Source of support: Nil

Conflict of interest: None

\section{INTRODUCTION}

Primary non-Hodgkin's lymphoma (NHL) of lacrimal sac is extremely uncommon and rare. ${ }^{1-3}$ The head and neck constitute the second most common region for extranodal non-Hodgkin's lymphoma after gastrointestinal tract. ${ }^{4,5}$ The most frequently involved sites of the head and neck are Waldeyer's ring (tonsils) and nasopharynx. Primary extranodal non-Hodgkin's lymphoma (PE-NHL) of the head and neck accounts for 10 to $20 \%$ of all cases of NHL. 6 Among the neoplasms of the lacrimal sac, epithelial tumors are the commonest. ${ }^{2,7-9}$ We hereby report a rare case of PE-NHL of the sac with extension to the nasolacrimal duct and further to ipsilateral nasal cavity. This rare presentation prompted us to report this case.

\section{CASE REPORT}

A 55-year-old female patient hailing from the rural region of the lesser Himalayas presented in our Outpatient Department (OPD) with chief complaints of swelling

Senior Resident

Department of ENT and Head and Neck Surgery, Dr Rajendra Prasad Government Medical College, Kangra, Himachal Pradesh India

Corresponding Author: Himanshu Kumar Mittal, Senior Resident Department of ENT and Head and Neck Surgery, Dr Rajendra Prasad Government Medical College, Kangra, Himachal Pradesh India, Phone: 9418452134, e-mail: drhimanshu.79@gmail.com below the medial canthus of left eye for the past 8 months and history of left-sided nasal obstruction for about 2 months. The swelling was of insidious onset, gradually progressive in size and associated with excessive tear flow and pus discharge from left eye. There was no history of visual impairment or blurring of vision from left eye.

It was accompanied with left-sided nasal obstruction for past 2 months which too was of insidious onset and gradually progressive in nature. It was not associated with any nose bleed or nasal discharge.

On examination, there was a swelling of size $1.5 \times$ $2 \mathrm{~cm}$ just below the medial canthus of left eye with erythema of the overlying skin as seen in Figure 1 (Clinical photograph of the patient showing swelling near left medial canthus). The swelling was firm in consistency and nontender on palpation. The regurgitation test was negative and lacrimal syringing was suggestive of complete blockage. There was no associated conjunctival congestion; eye movements and vision was normal. There was no proptosis. Nasal examination revealed a pinkish polypoidal mass which was firm in consistency and bled on touch. It could be probed all around except laterally. The blood investigations revealed a normal hemogram and blood counts. The liver and renal function tests were also within normal limits. Contrast enhanced computed tomography (CECT) of nose and paranasal sinuses revealed a heterogeneously enhancing mass involving left lacrimal sac and nasolacrimal duct with extension into left inferior meatus and nasal cavity as seen in Figure 2 (Axial section of CECT scan showing soft tissue density mass in left lacrimal sac region) and Figure 3 (Axial section of CECT scan showing soft tissue density mass in left lacrimal sac extending to nasolacrimal duct without bony erosion). It had caused expansion of middle turbinate and occlusion of the osteomeatal complex. There was resultant soft tissue density in the ipsilateral maxillary, ethmoid and frontal sinuses suggestive of concomitant sinusitis as seen in Figure 4 (Coronal section of CECT scan showing extension of soft tissue mass into left nasal cavity with concomitant maxillary sinusitis). There was no evidence of bony erosion. Needle biopsy from the swelling near the left medial canthus was suggestive of extranodal NHL. A simultaneous biopsy from the mass of left nasal 


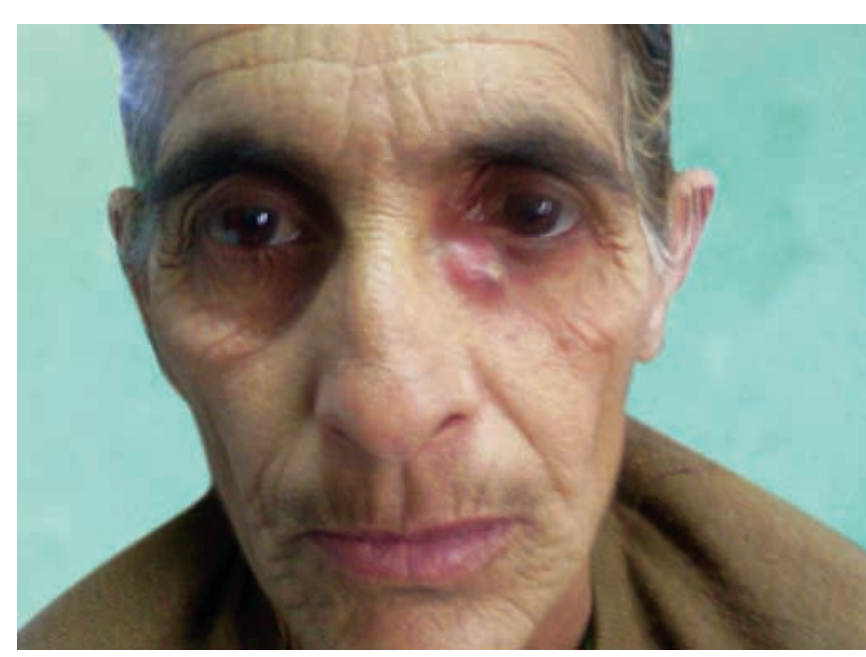

Fig. 1: Clinical photograph of the patient showing swelling near left medial canthus

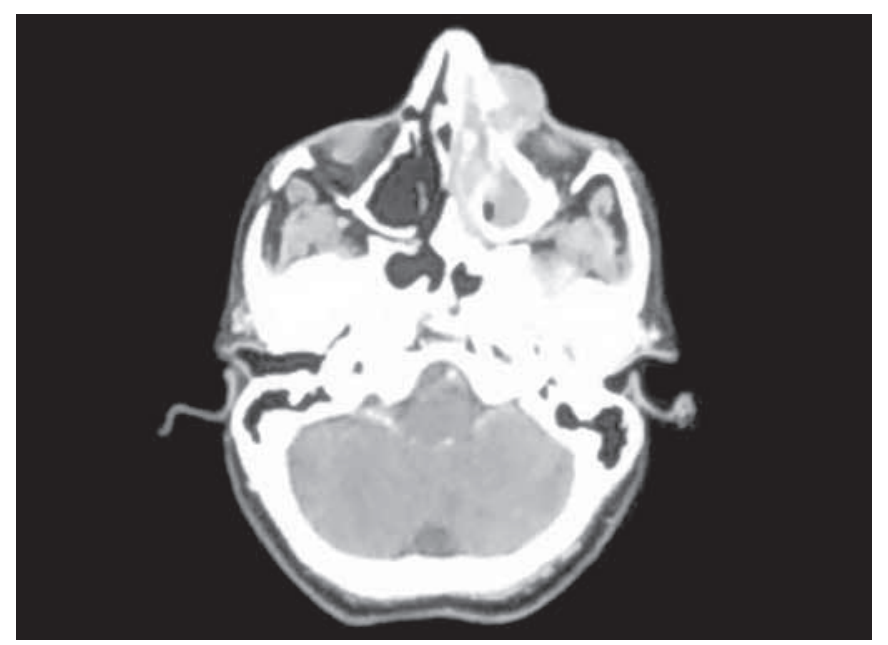

Fig. 3: Axial section of CT scan showing soft tissue density mass in left lacrimal sac extending to nasolacrimal duct without bony erosion

cavity was also performed and which too was suggestive of extranodal NHL. Thereafter, the patient received chemotherapy in the form of cyclophosphamide, hydroxydoxorubicin oncovine and prednisone ( $\mathrm{CHOP}$ ). Six cycles of chemotherapy were given followed by radiotherapy 30 Gy. The patient improved and is on regular follow-up.

\section{DISCUSSION}

The head and neck region is the second most frequent anatomical site of extranodal lymphomas after the gastrointestinal tract. ${ }^{4,5}$ Their distribution among different anatomical subsites of head and neck in decreasing order of frequency is: Waldeyer's ring (tonsils), nasopharynx, oral cavity, salivary glands, nasal cavity, paranasal sinuses $^{6}$. Primary NHL of the lacrimal sac is extremely uncommon. Moreover, we did not encounter any case with extension of the tumor to the nasal cavity through the nasolacrimal duct in the review of literature, to the

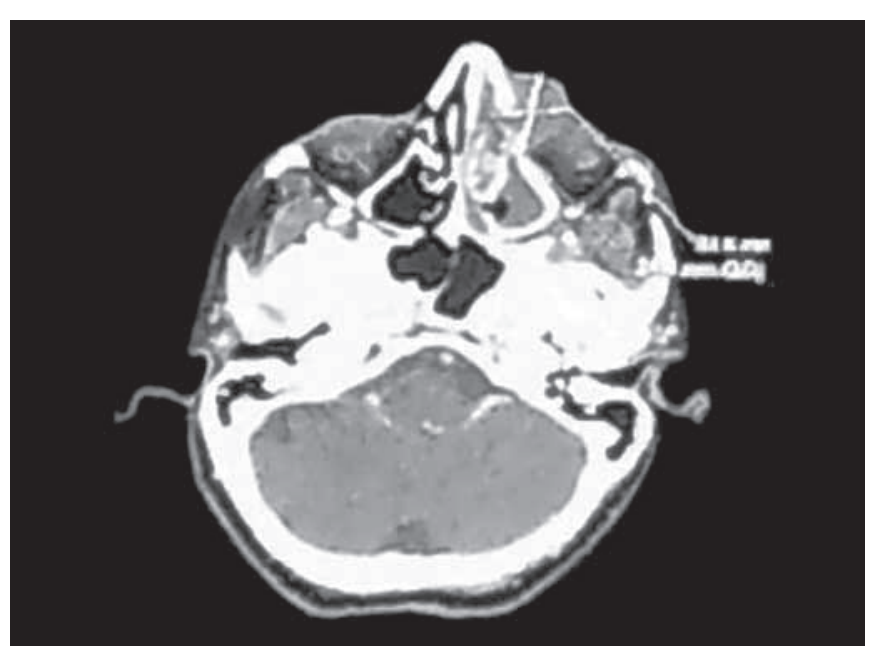

Fig. 2: Axial section of CT scan showing soft tissue density mass in left lacrimal sac region

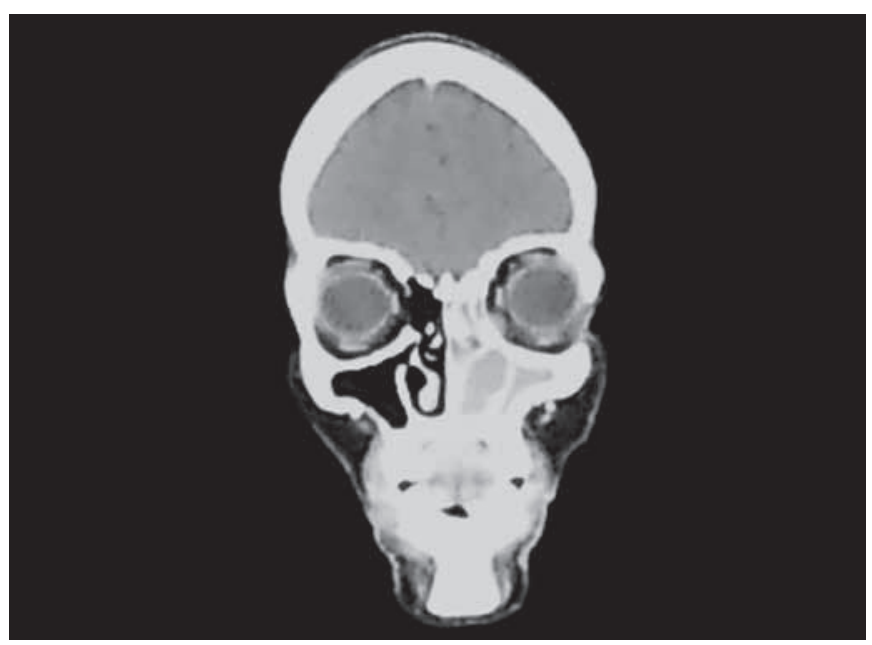

Fig. 4: Coronal section of CT scan showing extension of soft tissue mass into left nasal cavity with concomitant maxillary sinusitis

best of our effort. Malignant tumors of the lacrimal sac are uncommon per se. The commonest among the malignant tumors are those of epithelial origin. ${ }^{2,8,9}$ The various malignant epithelial tumors seen are squamous cell carcinomas, adenocarcinoma, epidermoid carcinoma, mucoepidermoid carcinoma, etc. Lymphoproliferative lesions of the lacrimal sac are less commonly seen and the primary NHL of the lacrimal sac is rare. ${ }^{1,3,10}$ Other less common and rare tumors include those originating from the mesenchymal elements, namely, the capillary and cavernous hemangiomas and hemangiopericytomas.

The typical presentation of a lacrimal sac tumor is as a medial canthal swelling with nasolacrimal duct obstruction. The most common presenting symptoms are epiphora and swelling in the lacrimal sac region ${ }^{1,3,7}$ occasionally bloody epiphora. This presentation can be easily confused with a lacrimal mucocele or a pyocele except for the consistency which is cystic in case of a mucocele as compared to firm in cases of neoplasms. 
The management of epithelial tumors of the lacrimal sac is primarily surgical. However, in case of lymphomas, the primary management consists of chemotherapy and radiotherapy. Cyclophosphamide, hydroxydoxorubicin, oncovine, prednisone regimen have been the standard conventional chemotherapeutic regimen in the treatment of NHL. Rituximab, a monoclonal anti-CD20 chimeric antibody has increased the cure rates in NHL and has been widely accepted for its treatment in addition to the conventional CHOP regimen. Though radiotherapy has been used as the sole modality of treatment with the dose of 30 to $40 \mathrm{~Gy}$, the recent trend has shifted to aggressive treatment with many centers recommending the use of chemotherapy followed by radiation. ${ }^{11}$

\section{CONCLUSION}

In patients presenting with epiphora along with the swelling in the lacrimal sac region, a careful examination and a thorough workup is mandatory since the presentation can easily be misdiagnosed as simple dacryocystitis with mucocele. The possibility of NHL should be kept in mind in such patients.

\section{REFERENCES}

1. Nakamura K, Uehara S, Omagari J, et al. Primary nonHodgkin's lymphoma of the lacrimal sac: a case report and a review of the literature. Cancer 1997;80(11):2151-2155.

2. Flanagan JC, Stokes DP. Lacrimal sac tumors. Ophthalmology 1978;85(12):1282-1287.
3. Sjo LD, Ralfkiaer E, Juhl BR, Prause JU, Kivela T, AuwHaedrich C, Bacin F, Carrera M, Coupland SE, Delbosc B, et al. Primary lymphoma of the lacrimal sac: an EORTC ophthalmic oncology task force study. Br J Ophthalmol 2006; 90(8):1004-1009.

4. Shaik MA, Waghray S, Kaleem SM, Morrthy S, Shaheen N. Primary extranodal B-cell lymphoma. Int J Exper Dent Sci 2012;1(1):30-33.

5. Vega F, Lin P, Medeiros LJ. Extranodal lymphomas of the head and neck. Ann Diagn Pathol 2005 Dec;9(6):340-350.

6. Economopoulos T, Fountzilas G, Kostourou A, et al. Primary extranodal non-Hodgkin's lymphoma of the head and neck in adults: a clinicopathological comparison between tonsillar and non-tonsillar lymphomas. (Hellenic co-operative Oncology Group). Anticancer Res 1998 Nov-Dec;18(6B): 4655-4660.

7. Venkitaraman R, George MK. Primary non-Hodgkin's lymphoma of the lacrimal sac. World J Surg Oncol 2007 Nov 6;5:127.

8. Saccogna PW, Strauss M, Bardenstein DS. Lymphoma of the nasolacrimal drainage system. Otolaryngol Head Neck Surg 1994;111(5):647-651.

9. Montalban A, Liétin B, Louvrier C, Russier M, Kemeny JL, Mom T, et al. Malignant lacrimal sac tumors. Eur Ann Otorhinolaryngol Head Neck Dis 2010 Nov;127(5):165-172.

10. Ryan SJ, Font RL. Primary epithelial neoplasms of the lacrimal sac. Am J Ophthalmol 1973 Jul;76(1):73-88.

11. Miller TP, Dahlberg S, Cassady JR, Adelstein DJ, Spier CM, Grogan TM, LeBlanc M, Carlin S, Chase E, Fisher RI. Chemotherapy alonecompared with chemotherapy plus radiotherapy for localized intermediate- and high-grade non-Hodgkin's lymphoma. N Engl J Med 1998;339(1):21-26. 